\title{
Rheumatic disease and the Australian Aborigine
}

\author{
Rachel A Roberts-Thomson, P J Roberts-Thomson
}

\begin{abstract}
Objective-To document the frequency and disease phenotype of various rheumatic diseases in the Australian Aborigine.

Methods-A comprehensive review was performed of the archaeological, ethnohistorical, and contemporary literature relating to rheumatic diseases in these indigenous people.

Results-No evidence was found to suggest that rheumatoid arthritis (RA), ankylosing spondylitis (AS), or gout occurred in Aborigines before or during the early stages of white settlement of Australia. Part of the explanation for the absence of these disorders in this indigenous group may relate to the scarcity of predisposing genetic elements, for example, shared rheumatoid epitope for RA, B27 antigen for AS. In contrast, osteoarthritis appeared to be common particularly involving the temporomandibular joint, right elbow and knees and, most probably, was related to excessive joint loading in their hunter gatherer lifestyle. Since white settlement, high frequency rates for rheumatic fever, systemic lupus erythematosus, and pyogenic arthritis have been observed and there are now scanty reports of the emergence of RA and gout in these original Australians.
\end{abstract}

Conclusion-The occurrence and phenotype of various rheumatic disorders in Australian Aborigines is distinctive but with recent changes in diet, lifestyle, and continuing genetic admixture may be undergoing change. An examination of rheumatic diseases in Australian Aborigines and its changing phenotype may lead to a greater understanding of the aetiopathogenesis of these disorders.

(Ann Rheum Dis 1999;58:266-270)

Ancestors of Australian Aborigines migrated to Sahul (continental land mass of Australia and New Guinea) 40-60 000 years before present and have continued to occupy the land to the present time. From a biological perspective the subsequent cultural and biological evolution of these isolated people in their unique environment can be viewed as an excellent opportunity to examine differences in disease expression in comparison with racial groups in other lands. If differences are observed they may provide clues to the aetioipathogenesis of these disorders. However, before examining the prevalence and phenotype of rheumatic diseases in the Australian Aborigines we need to acknowledge recent changes in genetic and environmental influences.

Up until white settlement the Australian Aborigines were considered to be genetically a fairly homogenous race but with some striking and distinctive regional variations particularly involving those HLA class II genes involved in immune responses. ${ }^{12}$ For example, in Aboriginal groups from different geographical regions, alleles with an apparent local origin accounts for $20-30 \%$ of the DRB1 gene frequencies. ${ }^{2}$ Furthermore, these indigenous people lived a hunter/gatherer lifestyle rich in cultural traditions but with little variation in their regional environmental influences. However, since settlement racial intermarriages have occurred with a mixture of white, Asian, Polynesian and Melanesian genes. In addition, there have been dramatic environmental changes including changes in diet and nutrition, lifestyle and exposure to various new infectious, chemical and toxic agents, etc. Thus today, tragically, the Australian Aborigines are characterised with high levels of obesity, diabetes, hypertension, chronic renal disease, hepatitis $\mathrm{B}$, alcoholism, chronic unemployment, and suicide. ${ }^{3}$ It is important therefore to recognise that changes in disease prevalence or phenotype over the past 200 years may reflect these influences and that contemporary observations may not necessary reflect the situation before white settlement. It should also be noted that rheumatic disease prevalence and perhaps phenotype may also change over time, for example, the probable increased prevalence of rheumatoid arthritis (RA) in the past 200 years.

\section{Sources of information}

The Australian Aborigines while rich in oral tradition have no written language and hence their own historical record from these people with regard to rheumatic diseases is not available. We must therefore seek other sources for this information. These alternative sources can be listed as (1) archaeological, (2) ethnographical/historical, (3) contemporary. Archaeological evidence of rheumatic disease is obtained from the examination of skeletal material obtained from aboriginal burial grounds or elsewhere and this study constitutes 
the subject of paleopathology. A recent monograph on the paleopathology of Australian Aborigines has been published using data collected from 4500 subjects from representative parts of the continent. ${ }^{4}$ Furthermore, according to Steinbock ${ }^{5}$ and Ortner and Putschar ${ }^{6}$ the rheumatic diseases that can be diagnosed from skeletal remains include osteoarthritis, vertebral hyperostosis, traumatic arthritis, RA, ankylosing spondylitis (AS), pyogenic arthritis, psoriatic arthritis, Reiter's syndrome, erosive osteoarthritis, and gout. Ethnographical evidence is obtained from the written historical records of observers who noted disease prevalence in their early contact with the Australian Aborigine. There is a rich source of this material and on many occasions involved informants who were medically trained. Contemporary data referred to the observation of current observers. In many instances the data are more complete but as discussed above, this information does not necessarily reflect the situation before white settlement.

\section{Rheumatic diseases}

OSTEOARTHRITIS

The paleopathological record describes extensive osteoarthritic changes in aboriginal skeletal remains where osteoarthritis is defined by the presence of one or more of the characteristic features of articular surface eburnation, erosions or pitting and marginal osteophytes. ${ }^{4}$ The predominant joints involved are the temporomandibular joint (TMJ), the spine, the elbow and the knee. Of interest, osteoarthritis of the elbow was particularly common and sometimes found in as many as $20 \%$ of the elbow joint examined. ${ }^{4}$ It was more common in men than women and involved the right elbow more than the left $\left(20 \%\right.$ versus $12 \% \chi^{2}=5.74$, $\mathrm{p}<0.02$ ) and distinct regional variation in frequencies was observed. It has been speculated that the explanation for the high frequency of the involvement of the right elbow in men could be related to the excessive joint loading and stress involved in repetitive motions such as spear throwing, throwing weapons and stones and in their hunter lifestyle.

In general, the frequency of knee arthritis was low for those nomadic people living hunter gatherer lifestyles. ${ }^{4}$ Osteoarthritis of both knees were particularly common in Queensland coastal women and were attributable to the high level mechanical stress involved in gathering shellfish where the women dug their feet into the thick mud looking for shellfish, producing a strong twisting mechanical strain on the knee joint.

High frequencies of TMJ arthritis have been recorded in most indigenous populations in Australia with the highest frequency $(60 \%)$ being found in the central Murray and South Coast region where arthritic changes were observed in subjects of both sexes and at a young age. ${ }^{4}$ The cause, presumably, for these accelerated changes relate to a multifactorial process involving jaw structure, dentition and tooth loss, type of bite, quantity of grit and abrasions and other inclusions in the food, food preparation and perhaps the use of teeth in net making, etc.

\section{RHEUMATOID ARTHRITIS}

There is no paleopathological or ethnographical evidence to support the existence of RA in indigenous people in Australia before or after white settlement. ${ }^{8}$ Furthermore, an analysis of the recent historical and contemporary literature reveals no descriptions of classic or definite RA occurring in these people. ${ }^{9}{ }^{10}$ We have recently commented on the rarity of RA in Australian Aborines and after a letter seeking further information, we have now been able to describe the clinical, laboratory, and immunogenetic features of seven Aborigines with probable or definite RA. ${ }^{11}$ It is of interest that these patients all derive from Northern Queensland and at least two of them have genetic evidence of prior racial mixture. Since this description we are now aware of a further 15 Aboriginal patients with RA all, however, having evidence of prior racial intermarriage (personal communication).

Why should the occurrence of RA be so rare in the Australian Aborigines? Part of the explanation may arise from the scarcity of the shared rheumatoid epitope in these people. The shared rheumatoid epitope is a motif on the MHC class II molecule involving antigen presentation as coded by a number of DR $\beta 1$ alleles. $^{12}$ This shared epitope is found in approximately $35 \%$ of healthy white populations but in $85 \%$ of patients with RA and may also be a risk factor for more severe disease outcome. The shared rheumatoid epitope occurs infrequently in the Australian Aborigine $^{2}$ but it was of interest to note its presence in four of the seven patients described above. In Australia, however, there is some regional variation where the shared rheumatoid epitope occurs with a higher frequency in the Aborigines of the Kimberley and Cape York (northern Queensland) region. ${ }^{12}$ It will be of interest to see if RA occurs more commonly in these populations of indigenous people.

RA also seems rare or non-existent in New Guinea Highlanders who probably have the same ancestral origins as the Australian Aborigine. ${ }^{13}$ It will be of interest to determine if these people also lack the shared rheumatoid epitope. RA is also absent in a rural Nigerian population. ${ }^{14}$ These people also lacked the shared rheumatoid epitope encoded by chromosome six.

GOUT

No paleopathological description of gouty arthritis exists in the skeletal record and there is no historical evidence for acute gout or chronic tophacous gout in Aboriginal subjects. ${ }^{4}$ In 1969 Emmerson and colleagues measured the serum uric acid concentration in 382 Gulf of Carpentaria Aborigines and significantly higher serum urate concentrations were noted. ${ }^{15}$ The men compared with the women had consistently higher concentrations in keeping with reports in all racial groups studied throughout the world and concentrations tended to increase with age in both sexes. Of 
interest was the finding that the mean serum urate concentration was significantly higher than those of a control white population by approximately $12 \%$. No factors other than racial were found to explain the difference. Furthermore, Emmerson stated in his discussion that despite the higher mean serum uric acid in Aborigines, clinical attacks of gouty arthritis were extremely rare. Indeed, inquiry from the Royal Flying Doctor Service and from many Aboriginal settlements scattered throughout Australia failed to record a single case of gout in an Australian Aborigine. An updated Medline search has also failed to find any description of acute or chronic tophacous gout in Australian Aborigines although we are now aware of several Aboriginal patients in the Top End who have crystal confirmed gout in association with chronic renal impairment. The scarcity of gout in Australian Aborigines should be contrasted with the situation in the Maori, other Polynesians and their ancestors where hyperuricaemia and clinical gout is very prevalent ${ }^{1617}$ and furthermore, in Micronesia, was also frequent in the past. ${ }^{18}$ The scarcity of acute gout and gouty arthritis in the Australian Aborigine is intriguing and requires further examination.

\section{SYSTEMIC LUPUS ERYTHEMATOSUS}

Three studies have revealed a high prevalence of systemic lupus erythematosus (SLE) in Australian Aborigines, one in Western Australia, ${ }^{19}$ one in northern Queensland, ${ }^{20}$ and one in the top end of the Northern Territory. ${ }^{21}$ In this latter and more complete study the prevalence was estimated (a minimal figure) at 1:1900, at least twice the estimated prevalence in non-Aboriginal Australians. High frequencies of renal disease and autoantibodies particularly to the Sm antigen (29\%) were identified, which were thought to contribute to the high mortality figures, (five year survival rate of $60 \%$ with $67 \%$ of the deaths resulting from infection). Further studies has suggested that the high frequency of SLE in these Northern Territory Aborigines may be related to the high occurrence of C4 null alleles (29\% compared with $17 \%$ of white controls), ${ }^{22}$ although another study has not confirmed this finding. ${ }^{23}$

OTHER CONNECTIVE TISSUE DISORDERS

We have personally observed the presence of scleroderma, dermatomyositis and ANCA related vasculitis in Australian Aborigines whose ancestral origins may involve prior genetic admixture.

\section{ANKYLOSING APONDYLITIS AND OTHER B27} RELATED ARTHROPATHIES

There is no paleopathological, ethnographical, historical or contemporary evidence to support the occurrence of AS in the indigenous Australian Aborigines with pure ancestry. Some initial confusion arose when examination of axial skeletal remains suggested $\mathrm{AS}^{4}$ but a close examination of the published illustrations indicates that they more probably represented subjects with localised vertebral ankylosis following an infective discitis or diffuse idi- opathic skeletal hyperostosis (DISH). Recent studies have revealed that AS is a genetic disorder with approximately $97 \%$ of the variance being determined by genetic factors. ${ }^{24}$ The HLA B27 and its allotypes is one of the important genes underlying the propensity to AS. In tissue typing on Australian Aborigines B27 appears to be at a very low frequency (compared with 6-8\% in white populations); indeed, in a study of 186 subjects from central Australia it was not detected. ${ }^{25}$ This absence could be in part, the explanation for the absence or low frequency of AS and other B27 related arthropathies in Australian Aborigines. As such, this finding in Australian Aborigines is similar to the absence of AS in other racial groups who also lack the B27 antigen. ${ }^{26}$

RHEUMATIC FEVER

The prevalence of rheumatic fever and associated streptococcal reactive polyarthritis is high in central and Northern Australian Aboriginal populations. ${ }^{27}{ }^{28}$ Indeed, one study in the Top End has shown the highest incidence rates of rheumatic fever worldwide with an annual incidence of acute rheumatic fever (19891993) between two to seven $/ 10^{4}$ children aged 4-14 years and 3\% of people having established rheumatic heart disease. ${ }^{27}$ The cause of rheumatic fever is thought not to be caused by any major predisposition based on ethnicity but by the high carriage rate of the M5 family (historical rheumatic fever associated $M$ types) group A streptococcus in Aboriginal subjects in tropical Australia, which in turn is related to overcrowding and continuous poor living conditions..$^{29}{ }^{30}$ It is not known whether acute rheumatic fever occurred in Australian Aborigines before white settlement but case descriptions of acute rheumatism were increasingly recorded after settlement. ${ }^{31}$

\section{JOINT AND BONE INFECTION}

Evidence of pyogenic arthritis leading to joint ankylosis and chronic bone infection has been commonly observed in the paleopathological record. ${ }^{4}{ }^{7}$ Widespread osteitis and periostitis frequently involving the long bones or the skull is thought to represent chronic bone infection. Webb discusses in detail whether this represents endemic treponemal infection ${ }^{4}$ (? Yaws) the spirochaete possibly being introduced by the Macassans who fished northern Australian seas for the sea cucumber or from a form of sexually transmitted syphilitic bony infection (although the presence of syphilis before colonisation seems unlikely). These bony infections seem particularly common in the central Murray Aboriginal populations where the frequency is as high as $17 \%$ although similar changes are seen in skeletal remains from most parts of Australia and are prominent around arid and tropical regions (but absent in Tasmanian Aborigines). ${ }^{4}$

Pyogenic arthritis is common in contemporary records frequently involving gonococcus reflecting the high prevalence of sexually related diseases in the Australian Aboriginal population. 
Table 1 Australian Aborigines. Diseases of the joints, bones, and muscles

\begin{tabular}{ll}
\hline Indigenous treatments & \\
Fractures & - splinting \\
Rheumatism & - emu oil liniment \\
& - hot ash massage \\
& - seated in hot ash mount \\
& - steam vapour bath over smouldering fire \\
& - animal urine as rubefacient \\
& - local bleeding with scarification, then suck afflicted part \\
& - dried and powdered sheaoak apple \\
& - fumigation over a smouldering fire on which green leaves had been \\
& thrown (Acacia lysiphloia or pinggi waterweed)
\end{tabular}

Table 2 Australian Aborigines. Indigenous treatments

\begin{tabular}{lll}
\hline $\begin{array}{l}\text { foint and muscle pain } \\
\text { Name }\end{array}$ & Preparation & Region \\
\hline Capparis umbonata & liniment & $\mathrm{Q}$ \\
Clerodendrum floribundum & mixture & NT \\
Crinum angustifolium & liniment & $\mathrm{Q}$ \\
Cymbopogon ambiguus & liniment & NT \\
Eremophilia longifolia & liniment & NT \\
Erythrophleum chlorostachys & application & Q \\
Eucalyptus comaldulenis & liniment & WA \\
Eucalyptus gum & liniment & NT \\
Eucalyptus tetrodonta & poultice & Q \\
Excoercaria parvifolia & liniment & NT \\
Tinospora smilacina & poultice & Q \\
Pandanus spiralis & poultice & NT \\
\hline
\end{tabular}

$\mathrm{Q}=$ Queensland, NT $=$ Northern Territory, WA $=$ Western Australia.

\section{RHEUMATISM}

The symptoms of joint and muscle pain and stiffness were widely noted in Aborigines in the ethnohistorical record as they were also in the white settlers. ${ }^{9}$ Rheumatism in the 19th century was defined as a kind of shifting phlegmasia or neuralgia, sometimes seated in the muscles, sometimes in the parts surrounding the joints; and at others, within them. Muscular rheumatism frequently involved the large muscles of the back, shoulder and neck and lumbago (acute pain in the lower back) was especially feared by Central Australian Aborigines as they considered it to be a sorcerer's evil. ${ }^{31}$ Rheumatism is now viewed as a nonspecific symptom common to a number of rheumatic and infectious disorders. Acute rheumatism is sometimes equated with acute rheumatic fever.

BACK PAIN

Honeyman and Jacobs performed a cross sectional survey on the occurrence of chronic backpain in a group of 55 Aborigines in the Pitjantjatjara homelands of Central Australia. ${ }^{32}$ They observed that nearly half of the adults experienced long term private spinal pain but because of the culture beliefs did not commonly make this pain public. They commented that their Aboriginal subjects did not regard back pain as a health issue and their lack of pain related behavour and cultural views of health gave these people no motivation to seek assistance regarding their back pain. Secret knowledge and sorcery played an important part in their culture with specific pain having separate and symbolic meaning. However, chronic low back pain had no such meaning. They concluded that cultural beliefs and practices influence how these people respond to back pain in themselves and in others including how and whether they presented to health professionals or sought involvement of others. The interaction in indigenous people between cultural beliefs, illness and illness behavour is an important and sensitive topic that will require further research.

\section{TRADITIONAL ANTI-RHEUMATIC TREATMENTS}

The Australian Aborigines had a number of intriguing treatments in their management of rheumatic symptoms. ${ }^{93}$ Table 1 gives a range of these. Blood letting was a common treatment used by indigenous people for a number of complaints including rheumatism and it is of interest that this same treatment was brought to Australia by the first colonial doctors. Stevens noted that the Adelaide tribe used the thin subcutaneous fat of the emu as an ointment-liniment. ${ }^{31}$ There has been a recent resurgence in the use of the emu oil as an antirheumatic application. Taplin recorded that the Narringerri people around the lower Murray lakes treated "rheumatism by a rude kind of vapour bath; the patient is placed on a platform made of sticks, underneath was placed red hot stones, or a few live coals, a rug is wrapped around the sufferer then some water weed called pinggi is taken wet from the lake shore and put on the hot stones or fire and the steam allowed to ascend around the naked body, and a perspiration is produced from which relief is often times obtained".

The Aboriginal Communities of the Northern Territory in their monograph describe a number of treatments of plant origin for joint and muscle pain (table 2). Most were prepared as a liniment or poultice. It should not be forgotten that aspirin is derived from the bark of the white willow tree while colchicine is derived from the bark of the of the chinchona tree.

\section{Discussion}

Documentation concerning rheumatic diseases in the Australian Aborigine is sparce and incomplete. We have little epidemiological data and the situation is further confounded by the rapid genetic and lifestyle changes occurring to these aboriginal populations. No published data are available concerning the frequency of such disorders as Paget's disease of bone, osteoporosis, soft tissue rheumatism, etc, in Australian Aborigines and there are only preliminary data concerning the more common rheumatic disorders. Table 3 shows the

Table 3 Frequency of rheumatic disease in Australian Aborigines

\begin{tabular}{|c|c|c|c|c|c|c|c|c|c|c|}
\hline & Osteoarthritis & $\begin{array}{l}\text { Vertebral } \\
\text { osteophytosis }\end{array}$ & Gout & $\begin{array}{l}\text { Ankylosing } \\
\text { spondylitis }\end{array}$ & $\begin{array}{l}\text { Pyogenic } \\
\text { arthritis }\end{array}$ & $\begin{array}{l}\text { Rheumatoid } \\
\text { arthritis }\end{array}$ & $\begin{array}{l}\text { Systemic lupus } \\
\text { erythematosus }\end{array}$ & $\begin{array}{l}\text { Low back } \\
\text { pain }\end{array}$ & $\begin{array}{l}\text { Rheumatic } \\
\text { fever }\end{array}$ & $\begin{array}{l}\text { Bone } \\
\text { infection }\end{array}$ \\
\hline Paleopathology & ++ & ++ & - & $+/-$ & + & - & & & & ++ \\
\hline $\begin{array}{l}\text { Ethnographic/ } \\
\text { historic }\end{array}$ & & & - & - & + & - & & & + & ++ \\
\hline Contempory & ++ & ++ & - & - & + & $+/-$ & ++ & - & ++ & + \\
\hline
\end{tabular}

$++=$ common, $+=$ described, $-=$ not described, blank $=$ no data. 
relative frequencies of these various rheumatic diseases in Australian Aborigines subdivided according to paleopathological, ethnohistorical or contemporary data. It should be observed that the common inflammatory arthritides of gout, RA, and B27 related arthropathies occur rarely in Australian Aborigines in contrast with their common occurrence in white populations. Part of the explanation for the absence of these rheumatic disorders may be because of the lack of predisposing genetic elements. In contrast, SLE, acute rheumatic fever, osteoarthritis of the elbow and TMJ occurs frequently and this is most probably explicable on genetic and lifestyle environmental factors. However, the total picture is far from complete. Further studies into the prevalence and phenotypes of rheumatic diseases occurring in the Australian Aborigine (particularly during times of environmental and genetic change) may give further insights into the aetiopathogenesis of these potentially disabling disorders.

We thank Miss M Barker for typing the manuscript and our colleagues Drs M J Ahern, M D Smith, D Bossingham, $\mathrm{C}$ Harrison, and E Stack for their useful comments. This review was written while Rachel Roberts-Thomson was engaged in student elective in the Top End of Northern Territory.

1 Gao X, Serjeantson SW. Diversity in HLA-DR4-related DR, DQ haplotypes in Australia, Oceania and China. Human Immunol 1991;32:269-76.

2 Lester S, Cassidy S, Humphreys I, Bennett G, Hurley CK, Boettcher B, et al. Evolution in HLA-DRB1 and major histocompatibility complex class II haplotypes of Australian Aborigines. Definition of a new DRB1 allele and distribution of DRB1 gene frequencies. Hum Immunol 1995;42: 154-60

3 Thomson N. Aboriginal health-current status. Aust NZ J Med 1984;14:705-18.

4 Webb S. Paleopathology of Aboriginal Australians. Melbourne: Cambridge University Press, 1995:167-76.

5 Steinbock RT. Paleopathological diagnosis and interpretation. Illinois: Charles C Thomas, 1976.

6 Ortner DJ, Putschar WGJ. Identification of pathological conditions in human skeletal remains. Smithsonian Contributions to anthropology no 28. Washington: Smithsonian Institution Press, 1981.

7 Mackay CV. Some pathological changes in Australian Aboriginal bones. Med J Aust 1938;14:537-55

8 Roberts-Thomson PJ. Does rheumatoid arthritis exist in the indigenous Australian Aboriginal population? [Letter] Med J Aust 1995;163:444-5.

9 Cleland JB. Disease amongst the Australian Aborigines Part IV. Diseases of the joints, bones and muscles. J Trop Med Hygiene 1928;31:202-5.

10 Douglas WA. Does rheumatoid arthritis exist in the indigenous Australian Aboriginal population? [Letter] Med J Aust 1996;164:191-2.
11 Roberts-Thomson PJ, Hedger S, Bossingham D. Rheumatoid arthritis and Australian Aborigines. Med J Aust 1998; 168:92-3.

12 Cregersen PK, Silver J, Winchester RJ. The shared epitope hypothesis. Arthritis Rheum 1987;30:1205-313.

13 Pile KD, Richens JE, Laurent RM, Bhatia K, Prasad ML, Lupiwa $\mathrm{T}$, et al. Arthritis in the highlands of Papua New Guinea. Ann Rheum Dis 1993;52:49-52.

14 Silman AJ, Ollier W, Holligan S, Birrell F, Adebajo A, Asuzu $\mathrm{MC}$, et al. Absence of rheumatoid arthritis in a rural Nigerian population. J Rheumatol 1993;20:618-22.

15 Emmerson BT, Douglas W, Doherty RL, Feigl P. Serum urate concentrations in the Australian Aboriginal. Ann Rheum Dis 1969;28:150-6.

16 Prio IAM, Rose BS, Harvey HPB, Davidson F. Hyperuricaemia, gout and diabetic abnormality in Polynesian people. Lancet 1966;i:333.

17 Chou CT, Lai JS. The epidemiology of hyperuricaemia and gout in Taiwan Aborigines. B J Rheumatol 1998;37:25862.

18 Rothschild BM, Heathcote GM. Characterization of gout in a skeletal population sample: presumptive diagnosis in a Micronesian population. Am J Phys Anthropol 1995;98: 519-25.

19 Bloor G, Rigby RJ, Richmond JM, Zilko PJ, Dawkins RI. Systemic lupus erythematosus in Australian Aborigines. [Abstract]. Aust NZ J Med 1982;12:553.

20 Grennan DM, Bossingham D. Systemic erythematosus (SLE): different prevalences in different populations of Australian Aboriginals. Aust NZ J Med 1995;25:182-3.

21 Ansley NM, Dunckley H, Bastian I, Currie BJ. Systemic lupus erythematosus in Australian Aborigine: high prevalence, morbility and mortality. Aust NZ J Med 1993;23. 646-51.

22 Ranford P, Serjeantson SW, Hay J, Dunckley H. A high frequency of inherited deficiency of complement componen C4 in Darwin Aboriginals. Aust NZ J Med 1987;17:420-3.

23 Anstey NM, Bastian I, Dunckley H, Currie BJ. Systemic lupus erythematosus (SLE): different prevalences in different populations of Australian Aborigines. Aust NZ J Med 1995;25:736-7.

24 Arnett FC, Chakraborty R. Ankylosing spondylitis: the disection of a complex genetic disease. Arthritis Rheum 1997; ection of a

25 Cleland LG, Hay JAR, Milazzo SC. Absence of HLA 27 and of ankylosing spondylitis in central Australian Aboriginals Scand J Rheumatol 1975;4 (suppl 8):30-5.

26 Khan MA. HLA-B27 and its subtypes in world populations. Curr Opin Rheumatol 1995;7:263-9.

27 Brennan RE, Patel MS. Acute rheumatic fever and rheumatic heart disease in a rural central Australian Aboriginal community. Med J Aust 1990;153:335.

28 Hartas J, Goodfellow AM, Currie BJ, Sriprakash KS. Characterisation of group A streptococcal isolates from tropical Australia with high prevalences of rheumatic fever: probing for signature sequences to identify members of the family of serotype 5. Microb Pathog 1995;18:345-54.

29 Carapetis JR, Currie BJ. Editorials - preventing rheumatic heart disease in Australia. Med J Aust 1998;168:425-9.

30 Patten BR. Rheumatic fever in the West Kimberly. Med J Aust 1981;1 (suppl 2):11-15.

31 Basedow H. Diseases of the Australian Aborigines. J Trop Med Hygiene 1932;35:209-32.

32 Honeyman PT, Jacobs EA. Effects of culture on back pain in Australian Aboriginals. Spine 1996;21:841-3.

33 Aboriginal Communities of the Northern Territory of Australia. Traditional bush medicine. Victoria: Greenhouse Publications, 1988 